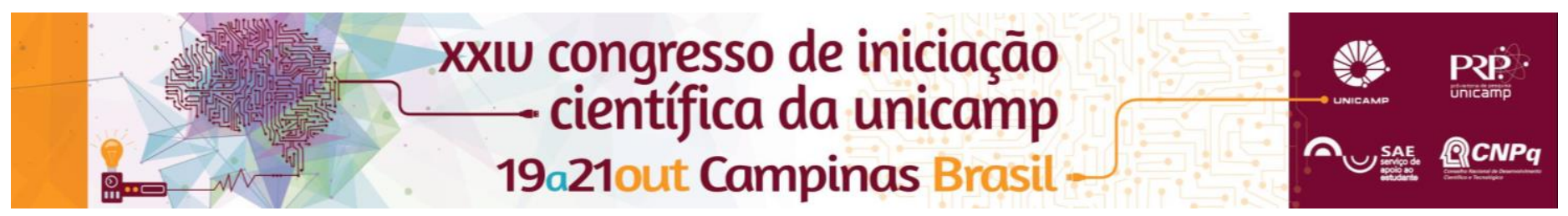

\title{
A controvérsia de Böhm-Bawerk/Hilferding e a crítica dos marginalistas da segunda geração à teoria do valor-trabalho de Marx
}

\author{
Enrique de Almeida Alvarez*, Mauricio Chalfin Coutinho
}

\begin{abstract}
Resumo
A pesquisa em questão consiste em um estudo das principais críticas realizadas pelos teóricos marginalistas da segunda geração, especificamente Eugen von Böhm-Bawerk, Philip Wicksteed e Friedrich von Wieser à teoria do valortrabalho proposta por Marx, com especial atenção ao debate que ficou posteriormente conhecido como a controvérsia de Böhm-Bawerk/Hilferding, considerando a defesa de Rudof Hilferding em favor da teoria marxista.
\end{abstract}

\section{Palavras-chave: \\ Valor, Böhm-Bawerk, Hilferding.}

\section{Introdução}

A controvérsia entre Böhm-Bawerk e Hilferding representa 0 embate entre duas correntes teóricas distintas no pensamento econômico, a corrente marginalista, baseada na teoria subjetiva do valor e na doutrina da utilidade marginal, e a corrente marxista, fundamentada na teoria do valor-trabalho.

O objetivo dessa pesquisa é realização de uma revisão bibliográfica da literatura que compreende o debate Böhm-Bawerk/Hilferding, de modo a elaborar um balanço geral da controvérsia. O estudo específico desse debate, por sua vez, apresenta-se relevante para a compreensão do desenvolvimento das concepções marxista e marginalista na história do pensamento econômico.

\section{Resultados e Discussão}

Tratando-se de uma revisão bibliográfica da controvérsia de Böhm-Bawerk/Hilferding, os resultados da pesquisa dizem respeito à organização e à análise dos argumentos e das divergências teóricas de ambos os lados do debate em questão.

Partindo das proposições teóricas de Carl Menger ${ }^{1}$, um dos principais expoentes da chamada "revolução marginalista", Böhm-Bawerk apresenta uma crítica sistemática à teoria marxiana. A crítica foi publicada em 1896 sob o título de "Karl Marx and the close of his system"2, após o lançamento do terceiro volume d'O Capital por Friedrich Engels.

Em linhas gerais, as críticas de Böhm-Bawerk às concepções teóricas d'O Capital apresentam dois eixos principais. Um deles é a inadequação empírica da teoria do valor-trabalho de Marx; o outro é a contradição entre os volumes primeiro e terceiro d'O Capital, no que diz respeito à teoria do valor. De acordo com Böhm-Bawerk, o equívoco de Marx em defender a proposição de que o trabalho, em sua forma abstrata e socialmente necessária, seria a única origem do valor das mercadorias e o determinante último de suas proporções de troca, teria resultado na incongruência e na completa inadequação de seu sistema. Isso se tornaria evidente no tratamento proposto pelo autor ao chamado problema da transformação, mediante a criação da categoria dos preços de produção e a consequente "negação" da lei do valor, no terceiro volume d'O Capital.

As críticas de Wicksteed e de Wieser, por sua vez, seriam consonantes com as de Böhm-Bawerk.
Em oposição às críticas marginalistas, Hilferding publica em 1904 a obra "Böhm-Bawerk's criticism of Marx"2, a qual apresenta uma contraposição sistemática aos argumentos de Böhm-Bawerk a partir da própria fundamentação da doutrina marxista. Para Hilferding, pela influência do individualismo metodológico e pelo equívoco na compreensão dos objetivos da análise de Marx, Böhm-Bawerk atribuiria diversas contradições à teoria marxiana, as quais seriam, em realidade, resultantes da própria interpretação inadequada do autor marginalista. De acordo com Hilferding, seria apenas por meio do estabelecimento do trabalho em sua forma social como medida do valor que a economia política seria determinada como uma ciência social e histórica, capaz de elucidar o determinismo social do fenômeno econômico e a evolução do movimento da sociedade de maneira objetiva.

No decorrer da pesquisa, foram incluídos outros autores e comentários: (1) análise de Bukharin sobre a teoria marginalista; (2) os comentários recentes à controvérsia (Cutler, Kliman, Saad Filho).

\section{Conclusões}

A controvérsia de Böhm-Bawerk/Hilferding retrata uma profunda divergência metodológica e analítica entre as correntes marxista e marginalista, resultando em uma permanente oposição teórica na compreensão dos fenômenos econômicos e na definição do conceito de valor. Enquanto a vertente marxista partiria de uma perspectiva social, histórica e objetiva, a corrente marginalista estaria relacionada a um enfoque não histórico, metodologicamente individual e subjetivo.

\section{Agradecimentos}

Agradeço ao CNPq pelo apoio financeiro e pelo aprendizado acadêmico por meio da iniciação científica.

Em especial, agradeço ao Prof. Dr. Mauricio Chalfin Coutinho, pela qualidade de sua orientação, pela paciência e pelo incentivo ao rigor acadêmico.

\footnotetext{
1 MENGER, C. Principles of economics. New York, NY: Free Press of Glencoe, c1950. 328p.

2 BÖHM-BAWERK, Eugen von; SWEEZY, Paul Marlor; HILFERDING, Rudolf (Coaut. De). Karl Marx and the close of his system. Philadelphia PA: Orion Eds., 1984.
} 